\title{
n-3 PUFA prevent metabolic disturbances associated with obesity and improve endothelial function in golden Syrian hamsters fed with a high-fat diet
}

\author{
Fatima Kasbi Chadli ${ }^{1,2,3}$, Agnès Andre ${ }^{1}$, Xavier Prieur ${ }^{1}$, Gervaise Loirand ${ }^{1}$, Anne Meynier ${ }^{4}$, \\ Michel Krempf ${ }^{1,3}$, Patrick Nguyen ${ }^{2,3}$ and Khadija Ouguerram ${ }^{1,3 *}$ \\ ${ }^{1}$ INSERM, UMR 915, IRT - UN L'institut du thorax, 8 quai Moncousu, BP 70721, 44007 Nantes Cedex 1, France \\ ${ }^{2}$ L'UNAM Oniris, Nutrition and Endocrinology Unit, National College of Veterinary Medicine, Food Science and Engineering, \\ Nantes F-44307, France \\ ${ }^{3}$ CRNH, Human Nutrition Research Centre of Nantes, CHU, Nantes F-44093, France \\ ${ }^{4}$ INRA, UR1368, Biopolymeres Interactions Assemblies, Rue de La Géraudière, BP 71627, 44316 Nantes, France \\ (Submitted 27 January 2011 - Final revision received 10 June 2011 - Accepted 11 July 2011 - First published online 16 September 2011)
}

\section{Abstract}

Glucose intolerance and dyslipidaemia are independent risk factors for endothelium dysfunction and CVD. The aim of the present study was to analyse the preventive effect of $n-3$ PUFA (EPA and DHA) on lipid and carbohydrate disturbances and endothelial dysfunction. Three groups of adult hamsters were studied for 20 weeks: (1) control diet (Control); (2) high-fat diet (HF); (3) high-fat diet enriched with $n$-3 PUFA (HFn-3) groups. The increase in body weight and fat mass in the HF compared to the Control group $(P<0 \cdot 05)$ was not found in the HFn-3 group. Muscle TAG content was similar in the Control and HF groups, but significantly lower in the HFn-3 group $(P=0 \cdot 008)$. Glucose tolerance was impaired in the HF compared to the Control group, but this impairment was prevented by $n-3$ PUFA in the HF $n$-3 group $(P<0 \cdot 001)$. Plasma TAG and cholesterol were higher in the HF group compared to the Control group $(P<0 \cdot 001)$, but lower in the HF $n$-3 group compared to the HF group $(P<0 \cdot 001)$. HDL-cholesterol was lower in the HF $n$ - 3 group compared to the Control and HF groups $(P<0 \cdot 0005)$. Hepatic secretion of TAG was lower in the HF $n-3$ group compared to the HF group $(P<0 \cdot 005)$, but did not differ from the Control group. Hepatic gene expression of sterol regulatory element-binding protein-1c, diacylglycerol $O$-acyltransferase 2 and stearyl CoA desaturase 1 was lower in the HF $n-3$ group, whereas carnitine palmitoyl transferase 1 and scavenger receptor class B type 1 expression was higher $(P<0 \cdot 05)$. In adipocytes and adipose macrophages, PPAR $\gamma$ and TNF $\alpha$ expression was higher in the $\mathrm{HF}$ and HF $n$ - 3 groups compared to the Control group. Endothelium relaxation was higher in the HF $n-3(P<0 \cdot 001)$ than in the HF and Control groups, and was correlated with glucose intolerance $(P=0.03)$ and cholesterol $(P=0.0003)$. In conclusion, $n$-3 PUFA prevent some metabolic disturbances induced by high-fat diet and improve endothelial function in hamsters.

Key words: n-3 PUFA: Dyslipidaemia: Glucose intolerance: Endothelial function: Hamsters

The metabolic syndrome is related to an increase in incidence of type 2 diabetes and CVD ${ }^{(1)}$. The disturbances associated with obesity (glucose intolerance, dyslipidaemia and postprandial hyperlipaemia) are independent risk factors for endothelium dysfunction, which is considered as an early marker of atherosclerosis ${ }^{(2)}$.

Among fatty acids, $n-3$ PUFA, especially EPA and DHA found in sea fish, have been reported to reduce the risk of arrhythmia and myocardial infarction in animal models ${ }^{(3)}$. Effect of $n-3$ PUFA on lipid metabolism is widely reported in rodents $^{(4,5)}$ and in human subjects ${ }^{(6,7)}$, with various findings on LDL- and HDL-cholesterol $\left(\mathrm{HDL}_{\mathrm{CH}}\right)$ depending on the type of study and animal species. Postprandial lipaemia response to $n-3$ PUFA also showed inconsistent data ${ }^{(8,9)}$. Glucose intolerance and insulin resistance are associated with a high risk of developing diabetes ${ }^{(10)}$. Results from human epidemiological studies indicated that $n-3$ PUFA reduce the development of insulin resistance and diabetes, whereas those from intervention studies in animal models present some divergences ${ }^{(11,12)}$.

Abbreviations: AUC, area under the curve; BW, body weight; CD11b, cluster of differentiation molecule 11b; Control, control diet; HDL ${ }_{\mathrm{CH}}$, HDL-cholesterol; HF, high-fat diet not enriched with $n$-3 PUFA; HFD, high-fat diet; HF $n$ - 3 , high-fat diet enriched with $n$ - 3 PUFA; LPL, lipoprotein lipase; MDA, malondialdehyde; PE, phenylephrine; RCT, reverse cholesterol transport; SCD1, stearyl CoA desaturase 1; SR-B1, scavenger receptor class B type 1; SREBP-1c, sterol regulatory element-binding protein-1c.

*Corresponding author: K. Ouguerram, fax +332280801 30, email khadija.ouguerram@univ-nantes.fr 
Although controversial, clinical studies with fish or fish oils have also shown a decrease in cardiovascular events in human subjects $^{(13)}$. Several mechanisms have been reported to explain this effect ${ }^{(14,15)}$. Whether or not fish intake is associated with future development of the metabolic syndrome and its related endothelium dysfunction has not been carefully evaluated. Endothelium dysfunction is related to the metabolic syndrome, and a diet enriched with DHA has been reported to enhance vasodilation mechanisms and to attenuate constriction responses in hyperlipidaemic, overweight men ${ }^{(16)}$. However, in experimental models, the influence of EPA and DHA on endothelium-dependent vasorelaxation has been controversial and seems to depend mostly on the experimental conditions and the animal species. Preincubation of aortic rings with EPA reduced the vessel-relaxing response to carbachol in healthy rats $^{(17)}$. On the same line, DHA-enriched diet failed to improve the altered endothelium-dependent aortic vasorelaxation in spontaneously hypertensive rats ${ }^{(18)}$ and in streptozotocin diabetic rats ${ }^{(19)}$, whereas EPA improved the endothelium-dependent relaxation of Otsuka Long-Evans Tokushima Fatty rats ${ }^{(20)}$.

The effect of $n-3$ has already been assessed in metabolic disturbances associated with obesity. However, few studies evaluated the involved parameters in the same animal and in the same conditions, and none of these used the hamster model. The present study is the first one that integrated different metabolic disturbances associated with obesity and the metabolic syndrome, in the same condition and using the hamster animal model. The hamster has been used as a valuable model because of its similarities to human subjects with regard to lipoprotein cholesterol metabolism ${ }^{(21)}$ and development of atherosclerotic lesions ${ }^{(22)}$.

In this study, we investigated the effect of $n$-3 PUFA on the prevention of some clinical and metabolic disturbances associated with obesity (dyslipidaemia, glucose intolerance, body composition) as well as endothelial dysfunction in hamsters fed with a high-fat diet (HFD).

\section{Materials and methods}

\section{Animals}

A total of thirty-six male golden Syrian hamsters were obtained from Janvier (Le Genest-St-Isle, France) at 8 weeks of age, weighing $80-90 \mathrm{~g}$. They were housed in colony cages with wood litter (four hamsters per cage) in a controlled environment $\left(22^{\circ} \mathrm{C}, 12 \mathrm{~h}\right.$ light $-12 \mathrm{~h}$ dark cycle) and received water and diet ad libitum. All experiments were performed according to the regulations for animal welfare of the French Ministry of Food, Agriculture and Fisheries. The experimental protocol adhered to European Union guidelines and was approved by the local animal use and care advisory committee.

\section{Diets}

Two HFD (21\% fat, w/w), either enriched (HF $n$-3) or not (HF) with $n$-3 PUFA, and a control chow $\operatorname{diet}(5 \%$ fat, w/w; Control) were used. Each of the HFD were designed with the same composition and contained $38.7 \%$ starch, $24.7 \%$ proteins, $21 \%$ lipids, $8.5 \%$ minerals, $6 \%$ cellulose and $1.2 \%$ vitamins. The lipid mixture consisted of $15 \%$ lard, $3.5 \%$ palm oil and $2.5 \%$ maize oil for HF. In the HFn-3 diet, $10 \%$ of lard $(1.5 \mathrm{~g})$ was replaced by an equivalent amount of $n-3$ PUFA oil mixture (Pierre Fabre Santé, Castres, France). In both diets, lipids provided about $45 \%$ of total energy content. The Control diet contained $23 \%$ protein, 58\% starch, 5\% lipids (2\% maize oil and 3\% palm oil), $8.5 \%$ minerals, $6 \%$ cellulose and $1.2 \%$ vitamins, and $13 \%$ of energy intake was provided by lipids. The experiments were performed in three groups of animals for a period of 20 weeks of consumption of one of the three diets. The fatty acid composition of the diets was analysed using a gas chromatograph with DB225 capillary column (J\&W Scientific, Agilent Technologies, Santa Clara, CA, USA; $60 \mathrm{~m} \times 0.25 \mathrm{~mm} \times 0.25 \mu \mathrm{m}$; Table 1).

\section{Body composition}

Hamsters were intraperitoneally injected with $150 \mathrm{mg} / \mathrm{kg}$ body weight (BW) ${ }^{2} \mathrm{H}$-labelled water $(99.9 \% \mathrm{D} / \mathrm{H}$; Eurisotop, Gif-sur-Yvette, France). Blood samples were collected before and $2 \mathrm{~h}$ after administering tracer injection. Plasma samples were frozen at $-20^{\circ} \mathrm{C}$ until analysis. Plasma ${ }^{2} \mathrm{H}$ enrichment was analysed by Fourier-transformed IR spectroscopy liquid using the sampling cell system (Perkin-Elmer, Les Ulis, France). Total body water was calculated from the dilution space of the isotope. A $74.4 \%$ fat-free mass hydration rate was assumed. Fat-free mass was thus calculated as total body water $/ 0 \cdot 744^{(23)}$.

\section{Glucose tolerance test}

An intraperitoneal glucose tolerance test was performed at 09.00 hours after being unfed for $18 \mathrm{~h}$. Eight hamsters of each group received $1 \mathrm{~g}$ of glucose per $\mathrm{kg}$ BW intraperitoneally.

Table 1. Lipid diet composition (\% of total fatty acids) measured by GC

\begin{tabular}{lccc}
\hline & $\begin{array}{c}\text { Control } \\
\text { group }\end{array}$ & $\begin{array}{c}\text { HF } \\
\text { group }\end{array}$ & $\begin{array}{c}\text { HF } n-3 \\
\text { group }\end{array}$ \\
\hline $14: 0$ & $1 \cdot 25$ & $1 \cdot 76$ & $1 \cdot 54$ \\
$15: 0$ & - & $0 \cdot 2$ & - \\
$16: 0$ & $33 \cdot 1$ & $30 \cdot 3$ & $29 \cdot 1$ \\
$18: 0$ & $4 \cdot 5$ & $12 \cdot 5$ & $10 \cdot 1$ \\
$14: 1$ & - & $1 \cdot 2$ & - \\
$16: 1 n-9$ & 0.08 & $0 \cdot 3$ & $0 \cdot 25$ \\
$16: 1 n-7$ & $0 \cdot 49$ & $2 \cdot 5$ & $2 \cdot 07$ \\
$18: 1 n-9$ & $34 \cdot 1$ & 40 & $34 \cdot 3$ \\
$18: 1 n-7$ & $0 \cdot 75$ & $2 \cdot 1$ & $0 \cdot 75$ \\
$20: 1 n-9$ & $0 \cdot 4$ & $0 \cdot 69$ & $0 \cdot 82$ \\
$18: 2 n-6$ & $24 \cdot 7$ & $9 \cdot 1$ & $16 \cdot 4$ \\
$20: 4 n-6$ & - & - & $0 \cdot 25$ \\
$18: 3 n-3$ & 0.5 & $0 \cdot 4$ & $0 \cdot 8$ \\
$20: 4 n-3$ & - & - & 0.09 \\
$20: 5 n-3$ & - & - & 2 \\
$22: 5 n-3$ & - & - & $0 \cdot 4$ \\
$22: 6 n-3$ & - & - & $1 \cdot 1$ \\
PUFA $n-6$ & $24 \cdot 7$ & $9 \cdot 1$ & $4 \cdot 5$ \\
PUFA $n-3$ & 0.5 & $0 \cdot 4$ & \\
\hline
\end{tabular}

Control, control diet; HF, high-fat diet; HFn-3, high-fat diet enriched with n-3 PUFA. 
Blood samples were obtained by retro-orbital puncture (under isofluran-induced anaesthesia) at 0 (basal), 10, 20, 30, 60 and $120 \mathrm{~min}$ and glycaemia was measured immediately using fresh blood (glucometer: Accu-Chek active; Roche Diagnostics, Mannhein, Germany). Areas under the curves (AUC) were calculated using GraphPad Prism (GraphPad Software, La Jolla, CA, USA).

\section{Plasma lipids}

Hamsters were food deprived for $18 \mathrm{~h}$ and blood was obtained by retro-orbital puncture to determine plasma lipids. Plasma was then separated by centrifugation $\left(4^{\circ} \mathrm{C}, 10 \mathrm{~min}, 3000 \mathrm{~g}\right)$. The following components were quantified in plasma: TAG, cholesterol and NEFA using enzymatic kits (Bio-Merieux, Marcy-l'Etoile, France and Wako Chemicals, Richmond, VA, USA). Cholesterol and TAG profiles were performed using fast protein liquid chromatography (AKTA FPLC SYSTEM; GE Healthcare, Piscataway, NJ, USA) ${ }^{(24)}$.

\section{Post-prandial lipaemia}

A measure of $450 \mu \mathrm{l}$ of olive oil per $100 \mathrm{~g}$ BW was given to animals unfed for $18 \mathrm{~h}$. Blood was taken from the eye orbital venous plexus every $2 \mathrm{~h}$ for $10 \mathrm{~h}$. Plasma was separated, TAG concentration was measured and AUC were calculated.

\section{Measurement of the in vivo secretion of VLDL TAG}

The effect of $n$-3 PUFA on the secretion of VLDL TAG by the liver was determined using tyloxapol (Sigma-Aldrich Chemicals, Lyon, France), a non-ionic surfactant that inhibits lipoprotein lipase (LPL) enzyme ${ }^{(25)}$. After being unfed for $18 \mathrm{~h}$, the hamsters were anaesthetised with isofluran and blood samples were taken from the eye orbital venous plexus. Tyloxapol $(500 \mathrm{mg} / \mathrm{kg})$ was injected via a jugular vein. Blood samples were taken at t0, just before injection of tyloxapol and then at $30 \mathrm{~min}(\mathrm{t} 30), 120 \mathrm{~min}(\mathrm{t} 120)$ and at $180 \mathrm{~min}$ (t180). The plasma TAG concentration was determined. The first $30 \mathrm{~min}$ after the injection of tyloxapol are required to reach detergent equilibration and to initiate lipoprotein accumulation ${ }^{(26)}$. The TAG accumulation is proportional to VLDL TAG secretion. TAG secretion rate for individual hamsters was therefore calculated using the linear increment between $\mathrm{t} 30$ and $\mathrm{t} 180^{(27)}$.

\section{Measurement of lipid content in liver and muscle}

About $30 \mathrm{mg}$ of hepatic tissue and $50 \mathrm{mg}$ of muscle were used to extract lipid using the Folch method ${ }^{(28)}$. Briefly, the tissue was homogenised with chloroform-methanol (2:1) and then centrifuged to recover the liquid phase. The solvent was washed with $0.9 \% \mathrm{NaCl}$ solution. After centrifugation, the lower chloroform phase containing lipids was evaporated and lipids were suspended in $0.5 \mathrm{ml}$ of ethanol. TAG and cholesterol were then measured using Biomérieux kit reagents (TAG: PAP 150, cholesterol RTU; Biomérieux, Marcy-l'Etoile, France).

\section{Evaluation of lipid peroxidation}

The measurement of malondialdehyde (MDA) concentration in plasma was performed by using an MDA kit (Sobioda, Montbonnot-Saint-Martin, France).

\section{Preparation of aortic rings and functional procedures}

A total of three or four hamsters from each group were anaesthetised with pentobarbital $(60 \mathrm{mg} / \mathrm{kg} \mathrm{BW})$. The thoracic aorta was dissected. The blood vessels were cleaned of connective tissue and cut into 2-mm rings. The rings were suspended in organ chambers of Mulvany myograph (Danish Mio Technology, Aarhus, Denmark). The arterial rings were challenged with $\mathrm{KCl}(60 \mathrm{mmol} / \mathrm{l})$ to evaluate their functional integrity and then contracted with increasing doses of phenylephrine (PE, $10^{-9}$ to $10^{-4} \mathrm{~mol} / \mathrm{l}$; Sigma-Aldrich Chemicals). The concentration of $\mathrm{PE}$ inducing $90 \%$ maximal contraction of the rings was used to contract the arteries. The rings were then relaxed with increasing doses of carbachol $\left(10^{-9}\right.$ to $10^{-4} \mathrm{~mol} / \mathrm{l}$; Sigma-Aldrich Chemicals).

\section{Separation of adipose tissue components}

Gonadal depots were transferred in a Falcon tube filled with Dulbecco's modified Eagle's media. The adipose tissue was then chopped thoroughly and resuspended in $10 \mathrm{ml}$ digestion solution ( $7 \mathrm{ml}$ Hanks' solution, $3 \mathrm{ml}$ of $7.5 \%$ BSA and $20 \mathrm{mg}$ collagenase type II; Sigma-Aldrich Chemicals). The digestion was performed at $37^{\circ} \mathrm{C}$ using a shaker at $100 \mathrm{rpm}$ for $20 \mathrm{~min}$. Then, the samples were kept at room temperature for $5 \mathrm{~min}$. After that, the adipocyte fraction (floating) was isolated, and the solution containing the stroma vascular fraction was filtered through a 100-mm cell strainer (BD Falcon, Isère, France), collected in a new tube and then centrifuged at $1500 \mathrm{rpm}, 4^{\circ} \mathrm{C}$ for $5 \mathrm{~min}$. The stroma vascular fraction pellet was suspended in $1 \mathrm{ml}$ of selection buffer (PBS, 2 mm-EDTA, 0.5\% BSA), centrifuged again and then the cluster of differentiation molecule 11b (CD11b)-positive cells were selected using CD11b micro-beads (Miltenyi Biotec, Bergisch Gladbach, Germany). Typically, $10 \mathrm{ml}$ of beads were used per ten million cells in $90 \mathrm{ml}$ selection buffer, and the cells were incubated for $20 \mathrm{~min}$ at $4^{\circ} \mathrm{C}$. After selection, the cells were washed with $1 \mathrm{ml}$ of selection buffer, centrifuged and then suspended in $50 \mathrm{ml}$ of selection buffer. The isolation of the positive fraction was performed using autoMACS Pro Separator (Miltenyi Biotec).

RNA extraction from liver, adipocyte and macrophage and gene expression analysis

Tissue samples for mRNA analysis were homogenised, and RNA was isolated using Trizol reagent (Invitrogen, Villebon sur Yvette, France). Real-time quantitative PCR analysis was performed as follows: $1 \mu \mathrm{g}$ of total RNA was reversetranscribed using $100 \mathrm{U}(100 \mathrm{~mol} / \mathrm{min})$ of Moloney murine leukaemia virus RT (Promega, Charbonnières-les-Bains, France). Real-time quantitative PCR was performed on the 7000 Sequence Detection System (GeneTool, Silicone Valley, 
Table 2. Effects of dietary $n$-3 PUFA on weight, percentage of fat mass, basal glycaemia, plasma lipid concentrations VLDL cholesterol (VLDL $\left.\mathrm{CH}_{\mathrm{CH}}\right)$, LDL cholesterol $\left(\mathrm{LDL}_{\mathrm{CH}}\right)$ and $\mathrm{HDL}$ cholesterol $\left(\mathrm{HDL}_{\mathrm{CH}}\right)$ (Mean values with their standard errors)

\begin{tabular}{|c|c|c|c|c|c|c|c|}
\hline & \multicolumn{2}{|c|}{ Control group } & \multicolumn{2}{|c|}{ HF group } & \multicolumn{2}{|c|}{$\mathrm{HF} n-3$ group } & \multirow[b]{2}{*}{$P$} \\
\hline & Mean & SEM & Mean & SEM & Mean & SEM & \\
\hline Weight (g) & $123 \cdot 7$ & $2 \cdot 8$ & $134 \cdot 9^{*}$ & $3 \cdot 2$ & $125 \cdot 1 \dagger$ & $3 \cdot 2$ & $P<0.01$ \\
\hline Fat (\%) & 13.6 & 1.6 & 17.60 & 1.5 & 13.9 & 1.0 & $P=0.09$ \\
\hline Glycaemia (g/l) & 0.96 & 0.07 & $1 \cdot 30^{*}$ & 0.08 & $1 \cdot 1 \dagger$ & 0.07 & $P<0.01$ \\
\hline TAG $(\mathrm{mmol} / \mathrm{l})$ & $1 \cdot 37$ & 0.1 & $2 \cdot 64^{*}$ & 0.24 & $1.83^{*} \dagger$ & 0.14 & $P<0.0001$ \\
\hline $\mathrm{CH}(\mathrm{mmol} / \mathrm{l})$ & $3 \cdot 31$ & 0.18 & $4.06^{\star}$ & 0.54 & $3.29 \dagger$ & 0.46 & $P<0.0005$ \\
\hline $\operatorname{NEFA}(\mathrm{mmol} / \mathrm{l})$ & 0.77 & 0.06 & 0.66 & 0.04 & 0.68 & 0.06 & NS \\
\hline $\operatorname{VLDL}_{\mathrm{CH}}(\mathrm{mmol} / \mathrm{l})$ & 0.208 & 0.003 & $0.596^{*}$ & 0.03 & $0.592^{*}$ & 0.031 & $P<0.0001$ \\
\hline $\mathrm{LDL}_{\mathrm{CH}}(\mathrm{mmol} / \mathrm{l})$ & 0.52 & 0.009 & $0.697^{*}$ & 0.035 & $0.646^{\star}$ & 0.033 & $P<0.0005$ \\
\hline $\mathrm{HDL}_{\mathrm{CH}}(\mathrm{mmol} / \mathrm{l})$ & 2.608 & 0.046 & $2 \cdot 831$ & 0.142 & $1.988^{*} \dagger$ & 0.104 & $P<0.0001$ \\
\hline
\end{tabular}

Control, control diet; HF, high-fat diet not enriched with $n$-3 PUFA; HFn-3, high-fat diet enriched with $n$-3 PUFA.

* Mean values were significantly different from those of the Control group $(P<0.05)$.

† Mean values were significantly different for the HFn-3 group from those of the HF group $(P<0.05)$.

CA, USA) with SYBR green MESAGREEN Master Mix Plus (Eurogentec, Angers, France). The reaction contained $10 \mathrm{ng}$ of reverse-transcribed total RNA, $500 \mathrm{~nm}$ forward and reverse primers and $5 \times$ SYBR green mix. Primer sequences are available on request. All reactions were performed at least in duplicate and cyclophilin RNA amplification was used as a reference. Each couple of primers was tested in successive dilutions of complementary DNA to analyse and validate its efficiency.

The expression of sterol regulatory element-binding protein-1c (SREBP-1c), stearyl CoA desaturase 1 (SCD1), diacylglycerol $O$-acyltransferase 2 , fatty acid synthase, PPAR $\gamma$, carnitine palmitoyl transferase 1 , microsomal TAG transfer protein, scavenger receptor class B type I (SR-B1), LPL and $\mathrm{TNF} \alpha$ was measured in liver.

The expression of CD11b (present only in macrophage membrane), SCD1, PPAR $\gamma$, fatty acid synthase, LPL and TNF $\alpha$ was measured in adipocytes and adipose tissue macrophages.

\section{Statistics}

Results were expressed as mean values and standard errors of the mean. Statistical analyses were performed using Statview software (SAS Institute Inc., Cary, NC, USA). Two-way repeated measures ANOVA followed by Fisher's protected least significant difference (PLSD) test were performed to estimate the effect of group and $n$-3 PUFA enrichment diet on obtained values. A simple regression was used to evaluate the correlation among variables. Differences were considered significant at $P<0.05$.

\section{Results}

Effects of dietary n-3 PUFA on body weight, body fat percentage, muscle lipid content and glucose tolerance

At the end of 20 weeks, the HF group had a higher BW than the Control group $(P<0 \cdot 05)$, and the BW of the HFn-3 group was lower than that of the HF group $(P<0.05)$ and did not

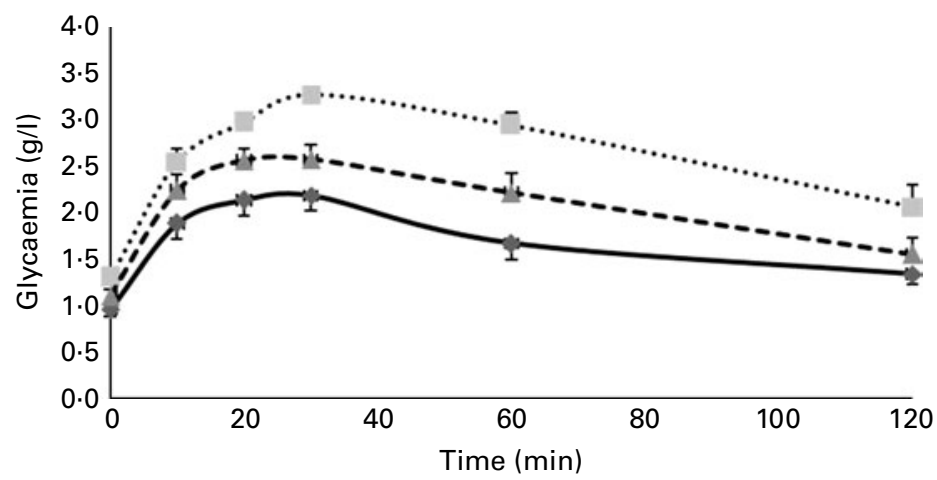

\begin{tabular}{cccccccc}
\hline & \multicolumn{2}{c}{ Control group } & \multicolumn{2}{c}{ HF group } & \multicolumn{2}{c}{ HFn-3 group } & $P$ (ANOVA) \\
\hline & Mean & SEM & Mean & SEM & Mean & SEM & \\
\hline AUC & 201.98 & 19.48 & $321.19 *$ & 13.40 & $246.63 \dagger$ & 15.85 & 0.0003 \\
\hline
\end{tabular}

Fig. 1. Effect of different diets on glycaemia after an intra-peritoneal injection of glucose (1 g/kg body weight). Values were measured in control diet (Control, ——), high-fat diet (HF, ...........) and high-fat diet enriched with $n-3$ PUFA (HFn-3, -.-.--) groups at t0, t10, t20, t30, t60 and t120 min. Area under the curve $(A \cup C)$ values are given as means with their standard errors represent by vertical bars for a group of six to eight hamsters. ${ }^{\star}$ Mean values were significantly different from those of the Control group $(P<0.05)$. $†$ Mean values were significantly different for the HF $n-3$ group from those of the HF group $(P<0.05)$. 
differ from the Control group (Table 2). A higher percentage of fat body mass was observed in the HF group compared to the Control group $(P=0.048)$, whereas fat percentage tended to be lower in the HFn-3 group compared to the HF group $(P=0.07)$ and did not differ from the Control group. Muscle TAG content was similar in the Control group $(4.01($ sem 0.80$) \mathrm{mg} / \mathrm{g}$ ) and HF group $(4.76($ Sem 0.23$) \mathrm{mg} / \mathrm{g}$ ), but was significantly lower in the HF $n$-3 group (2.29 (SEM $0 \cdot 29) \mathrm{mg} / \mathrm{g}$ ), with $P=0 \cdot 008$. No difference was observed in cholesterol content among groups.

Basal blood glucose was higher in the HF group than in the Control and HF $n-3$ groups $(P<0 \cdot 05$; Table 2$)$. After intraperitoneal injection of glucose, the HF group showed an impairment of glucose tolerance assessed by glycaemia AUC compared to both Control $(P<0.0001)$ and HF $n-3(P<0.005)$ groups. No significant difference was observed between the Control and HFn-3 groups (Fig. 1).

\section{Effects of dietary n-3 PUFA on plasma lipids}

The effect of diets on plasma lipids is shown in Table 2. Plasma TAG and cholesterol were higher in the HF group $(P<0.001)$ compared to the Control group, whereas the HF $n$-3 group showed a lower concentration of TAG $(P<0.01)$ and cholesterol $(P<0.001)$ compared to the HF group. TAG concentration was higher in the HFn-3 group compared to the Control group. No difference was observed in plasma NEFA concentrations.

Data from fast protein liquid chromatography are shown in Table 2. Cholesterol level was higher in VLDL and LDL in both HF and HF $n-3$ groups compared to the Control group $(P<0.005)$, whereas it was lower in HDL of the HFn-3 group compared to both Control and HF groups $(P<0 \cdot 0005)$. Diet enriched with $n-3$ PUFA significantly decreased VLDL TAG. No change was observed in LDL and HDL TAG content among groups

\section{Effect of dietary n-3 PUFA on endogenous TAG secretion and liver lipid content}

In vivo TAG secretion rate was measured after administering an intravenous injection of tyloxapol (Fig. 2). The results show that plasma TAG was higher in the HF group compared to Control and HF $n-3$ groups at t30 $(P<0.05)$ and t120 $(P<0 \cdot 01)$ after tyloxapol injection. No significant difference was observed at t180 between the Control and HF groups $(P=0 \cdot 11)$, whereas plasma TAG in HF $n-3$ group was lower than that in the HF group $(P=0.002)$ and tended to be lower compared to the Control group $(P=0 \cdot 06)$. The HF $n-3$ group presented a lower TAG secretion rate (1.19) (SEM $0 \cdot 14) \mathrm{mmol} / \mathrm{l}$ per $\mathrm{h})$ compared to the HF group $(1.84$ (sem0.22) $\mathrm{mmol} / \mathrm{l}$ per $\mathrm{h} ; P=0.006)$ and tended to decrease compared to the Control group (1.46 (sem0.20) mmol/l per h; $P=0 \cdot 098)$. Liver TAG content was higher in the HF $n-3$ group compared to the Control group $(P<0.05)$, but lower compared to the HF group $(P<0 \cdot 05)$. No difference was observed in hepatic cholesterol content among the three groups.
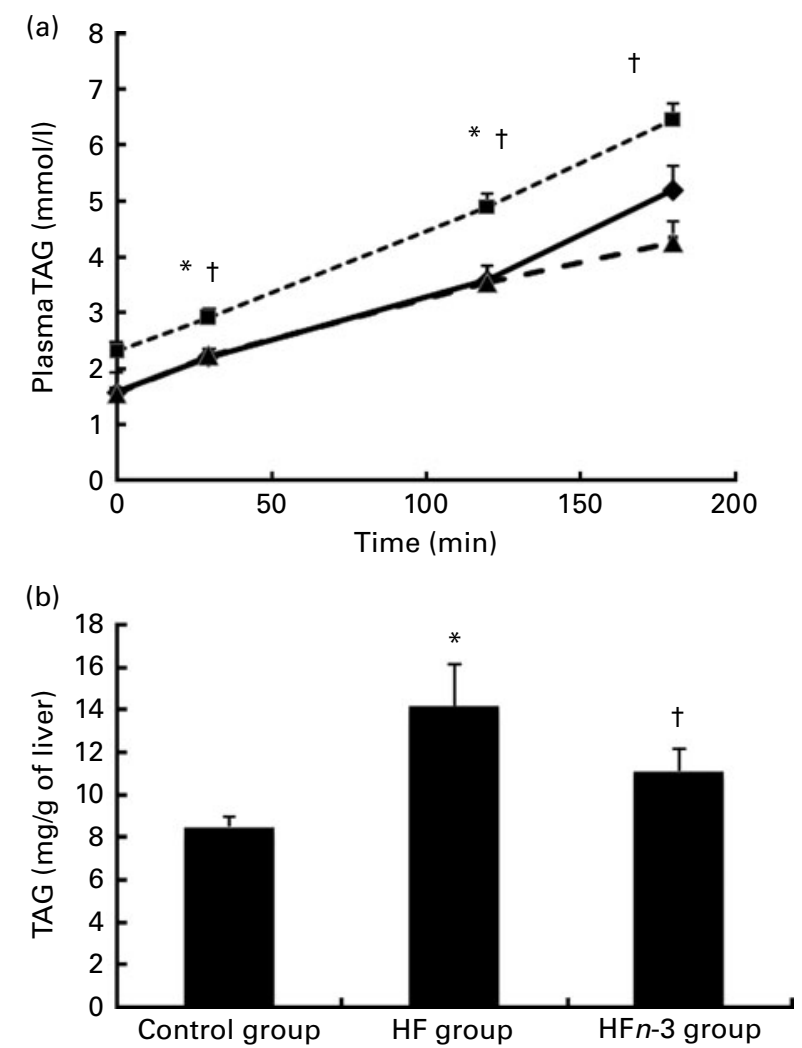

Fig. 2. (a) Effect of dietary fats on hepatic TAG secretion. Hamsters were fed with different types of diets for 20 weeks. After $18 \mathrm{~h}$ of food deprivation, retro-orbital blood sample was drawn and tyloxapol was injected. Thereafter, blood samples were collected at fixed time intervals ( $30 \mathrm{~min}, 2 \mathrm{~h}$ and $3 \mathrm{~h}$ ) and plasma TAG level was determined. Values are means, with their standard errors represented by vertical bars $(n 6)$. (b) TAG content in liver given in $\mathrm{mg} / \mathrm{g}$ of liver. ${ }^{*}$ Mean values were significantly different from those of the control diet (Control, $-\bullet ; P<0.05$ ) group. $†$ Mean values were significantly different for the high-fat diet enriched with $n-3$ PUFA (HFn-3, - - - - -) group from those of the high-fat diet (HF, -- $---; P<0.05)$ group.

\section{Post-prandial lipaemia}

AUC of plasma TAG after olive oil oral administration was higher in the HF group compared to the Control group $(P<0 \cdot 05$; Fig. 3) and was not significantly different from that of the HF $n$-3 group $(P=0 \cdot 11)$. Nevertheless, plasma TAG concentration was significantly lower in the HFn-3 group at 6,8 and $10 \mathrm{~h}$ after oral administration compared to the $\mathrm{HF}$ group, although it did not differ from the Control group at these time periods.

\section{Lipid peroxidation}

The measurement of MDA in plasma of the different groups showed no difference between the Control (11.59 (SEM 1.19) $\mu \mathrm{mol} / \mathrm{l})$ and HF (13.75 (SEM1.59) $\mu \mathrm{mol} / \mathrm{l})$ group. MDA concentration in the HFn-3 group $(27 \cdot 64(\operatorname{sem} 2 \cdot 21) \mu \mathrm{mol} / \mathrm{l})$ was higher compared to both the Control and HF groups $(P<0 \cdot 001)$.

\section{Endothelial function}

The contraction produced in response to $\mathrm{PE}$ was the same in all the three groups, whereas carbachol added to 


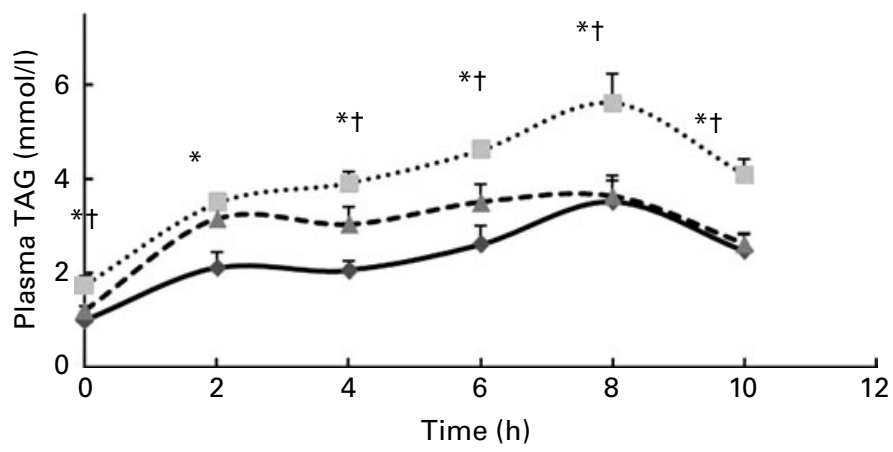

\begin{tabular}{cccccccc}
\hline & \multicolumn{2}{c}{ Control group } & \multicolumn{2}{c}{ HF group } & \multicolumn{2}{l}{ HFn-3 group } & $P($ ANOVA) \\
\hline & Mean & SEM & Mean & SEM & Mean & SEM & \\
\hline AUC & 21.17 & 2.86 & 30.19 & 1.80 & 25.86 & 1.65 & 0.02 \\
\hline
\end{tabular}

Fig. 3. Effect of different diets on TAG after gavages with olive oil and area under the curve (AUC) measurement. Values are means, with their standard errors represented by vertical bars. * Mean values were significantly different for the high-fat diet (HF, ........) group from those of the control diet $($ Control, $-\varangle$; $P<0.05)$ group. † Mean values were significantly different for the HF group from those of the high-fat diet enriched with $n-3$ PUFA (HF $\left.n-3,---A_{--} ; P<0.05\right)$ group.

pre-constricted rings with $10^{-6} \mathrm{M}$ of $\mathrm{PE}$ showed significant difference of relaxation between the HF $n$ - 3 group compared to both the Control and HF groups at $10^{-6}, 10^{-5}$ and $10^{-4} \mathrm{M}$-carbachol with $P<0 \cdot 01$. Vessels of HFn-3 hamsters were more sensitive to carbachol $\left(10^{-6} \mathrm{M}\right)$-induced relaxation ( 47.5 (SEM 5.0) \%) compared to the Control (22.13 (SEM 5.7)\%; $P=0.01)$ and HF groups (7.28 (SEM 4.85)\%; $P<0.0005)$. Control and HF groups did not differ significantly $(P=0.09)$. At $10^{5}$ and $10^{4} \mathrm{M}$ of carbachol, HF $n-3$ hamsters vessel relaxation remained higher $(P<0.005)$, whereas no difference was observed between the Control and HF groups (Fig. 4).

Endothelium-dependant vasorelaxation correlated negatively with glucose intolerance $(r-0.591, P=0.033)$ and with total cholesterol concentration $(r-0 \cdot 84, P=0 \cdot 0003)$.

\section{Gene expression in liver, adipocytes and macrophages}

Hepatic SREBP-1c mRNA expression was strongly activated in the HF group compared to the Control group $(P<0.005)$, whereas it reduced in the HF $n-3$ group $(P<0 \cdot 005)$. Diacylglycerol $O$-acyltransferase 2 and SCD1 expression was lower in the HFn-3 group compared to both the Control and HF groups $(P<0.05)$. There was no significant difference for fatty acid synthase $(P=0.08)$. PPAR $\gamma$ mRNA expression showed no significant increase with $n$-3 PUFA compared to the Control and HF groups. Carnitine palmitoyl transferase 1 gene expression was higher in the HFn-3 group $(P<0.05)$ compared to the HF group, whereas it did not differ from the Control group. Hepatic mRNA expression of LPL and TNF $\alpha$ genes was not affected by diet. SR-B1 gene expression was higher in the HF $n$-3 group compared to both the Control and HF groups ( $P<0.05$; Fig. 5$)$.

In macrophages, the expression of PPAR $\gamma$ and TNF $\alpha$ was higher in the HF and HFn-3 groups compared to the Control group $(P<0 \cdot 05)$. No difference was showed for fatty acid synthase, LPL and SCD1. In adipocyte, expression of these genes was not different among the three groups.
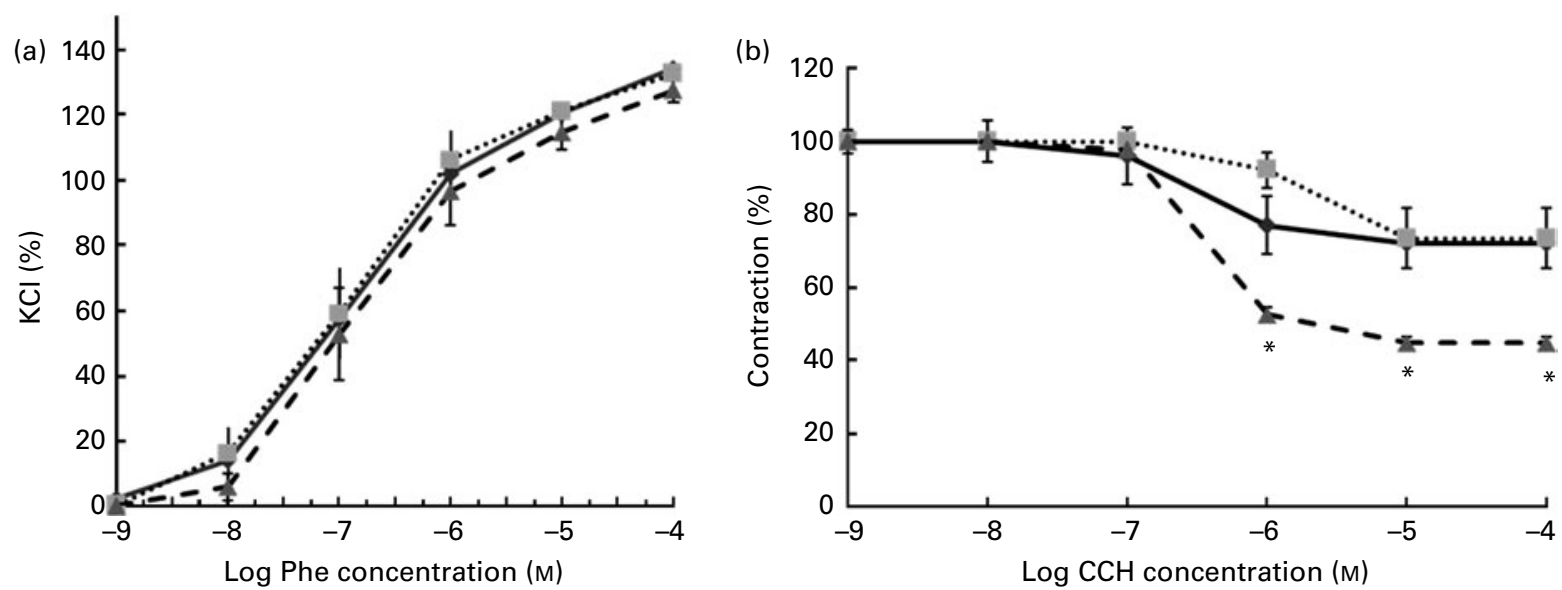

Fig. 4. Dose-response curves to (a) phenylephrine (Phe) and (b) carbachol (CCH) of control diet (Control, - - - ), high-fat diet (HF, ...........) and high-fat diet enriched with $n$-3 PUFA (HFn-3, - - - ) groups. Values are means with their standard errors represented by vertical bars $(n 4)$ ) ${ }^{*}$ Mean values were significantly different for the HFn-3 group from those of the HF and Control groups $(P<0.001)$. 

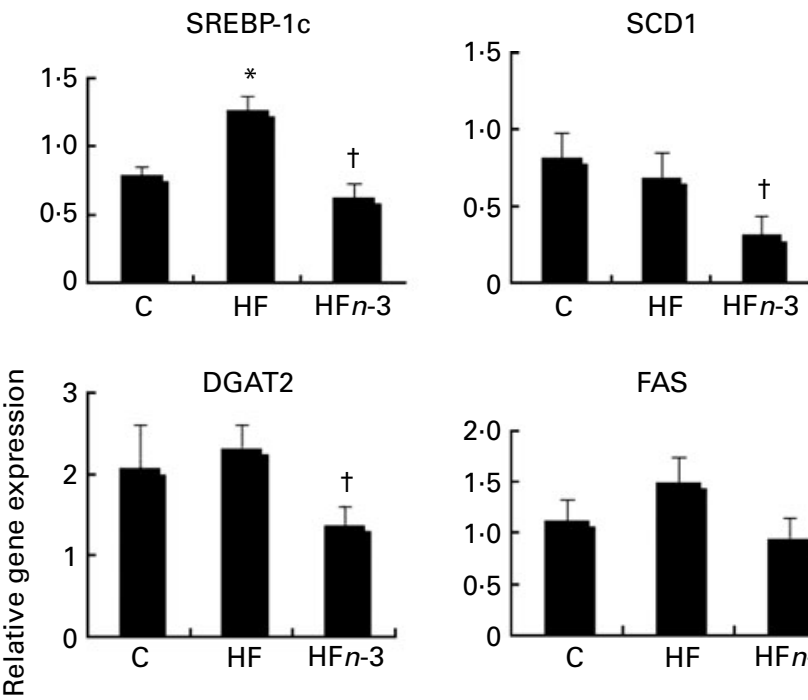

FAS
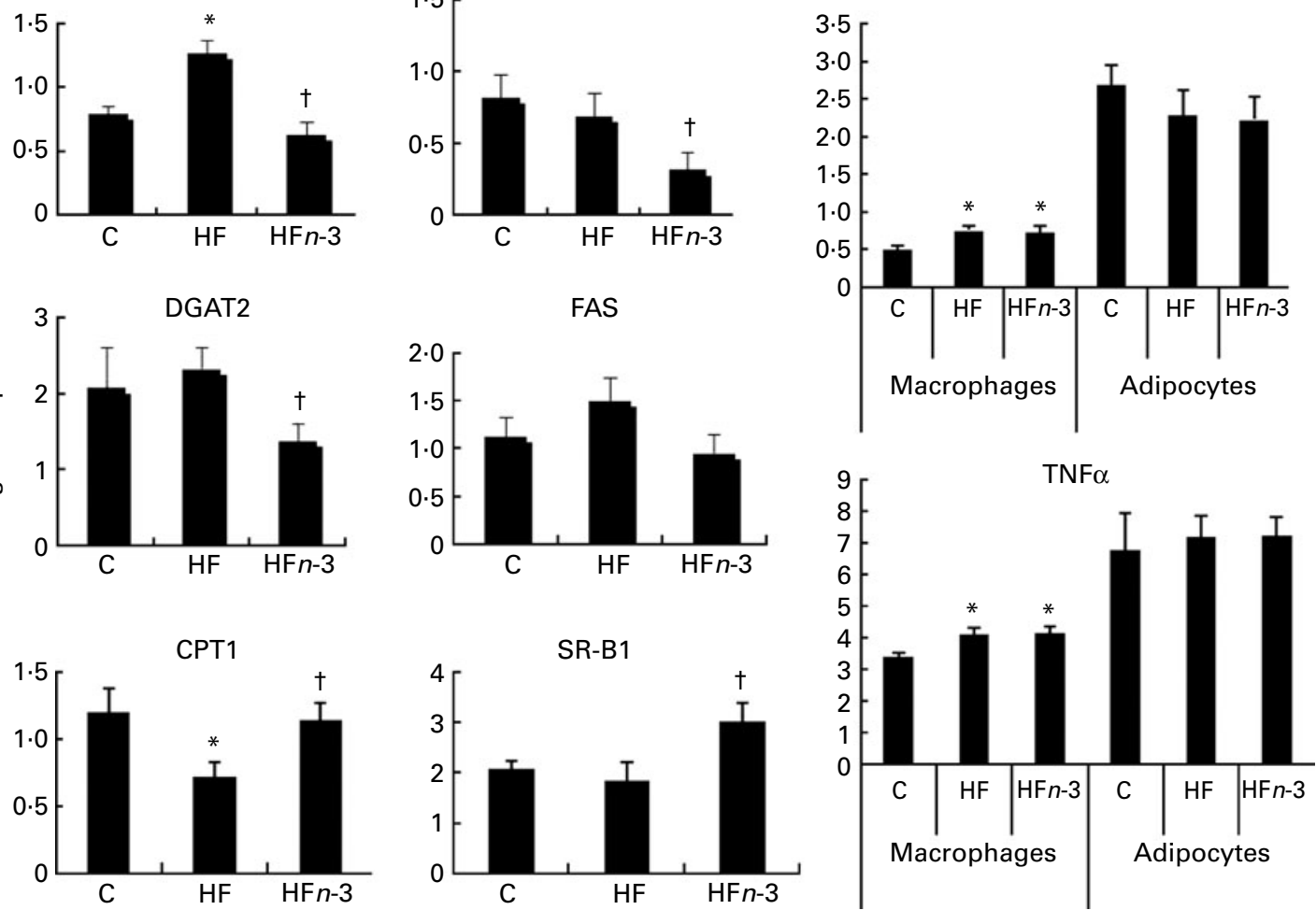

Fig. 5. Relative gene expression of sterol regulatory element-binding protein 1c (SREBP-1c), stearyl CoA desaturase 1 (SCD1), diacylglycerol O-acyltransferase 2 (DGAT2), fatty acid synthase (FAS), PPAR $\gamma$, scavenger receptor class B type 1 (SR-B1) and carnitine palmitoyl transferase 1 (CPT1) in hepatic tissue. PPAR $\gamma$ and TNF $\alpha$ in adipose tissue macrophages and adipocytes of control diet (C), high-fat diet (HF) and high-fat diet enriched with $n-3$ PUFA (HFn-3) groups. Values are means, with their standard errors represented by vertical bars $(n 6) .^{*}$ Mean values were significantly different from those of the Control group $(P<0.05)$. † Mean values were significantly different from those of the HF $n-3$ group $(P<0.05)$.

\section{Discussion}

In the present study, we investigated the preventive effect of $n$-3 PUFA on the development of metabolic syndrome-associated disturbances induced by a HFD in golden Syrian hamster.

We reported that $n$-3 PUFA enrichment ameliorated metabolic syndrome-associated cardiovascular risk by preventing BW gain, dyslipidaemia, high postprandial lipaemia and glucose intolerance. Despite the fact that HFD did not impair endothelial-dependent vasorelaxation in the $\mathrm{HF}$ group compared to the Control group, $n-3$ PUFA improved it in the HFn-3 group.

We showed that HFD induced obesity (as BW gain and increase in fat mass percentage) in the HF group compared to the Control group, but $n-3$ PUFA enrichment attenuated BW gain and reduced fat mass percentage in the HF $n-3$ group compared to the HF group. Data from studies on the effect of $n-3$ PUFA on BW reduction are inconsistent. In human studies, the effect on BW was only effective when $n-3$ PUFA were combined with a BW loss regimen ${ }^{(29,30)}$. Some studies described a limited extension of adipose tissue in rats ${ }^{(31,32)}$, mice ${ }^{(33,34)}$ and salmon ${ }^{(35)}$ explained by different mechanisms, whereas in other studies no effect was observed $^{(36)}$ or observed only in mice fed with high-fat/ high-sucrose diet ${ }^{(37)}$. In our study, we showed a lower hepatic SCD1 gene expression in the HF $n-3$ group. The inhibition of
SCD1 is described to protect from HFD-induced obesity related to an up-regulation of genes involved in $\beta$-oxidation and a down-regulation of lipogenesis gene expression, as shown in mice $\mathrm{SCD}^{-/-(38)}$. However, another study in mice reported a decrease in SCD1, but with no consequence on $\mathrm{BW}^{(39)}$

Impaired glucose tolerance is widely described as a cardiovascular risk factor ${ }^{(10)}$. In our study, the effect of EPA and DHA enrichment on glucose tolerance, as assessed by fasting glycaemia and AUC, was impaired in the HF group and prevented by $n-3$ PUFA. The same result was reported in rodents ${ }^{(40,41)}$ and human subjects, and was related to an increasing membrane fluidity and GLUT4 transport $^{(42)}$ or affecting insulin receptor and insulin receptor substrate expression and protein abundance ${ }^{(43)}$. The prevention of BW gain associated with low muscle lipid content in the HF $n$ - 3 group can also explain the improvement of glucose tolerance measured in this group. Indeed, it was reported that BW loss induced by energy restriction decreased muscle lipid content in obese individuals with and without type 2 diabetes ${ }^{(44)}$, in conjunction with enhancement of insulin sensitivity ${ }^{(45)}$

Obesity is associated with an increase in the recruitment of adipose tissue macrophages ${ }^{(46,47)}$. Interventions that inhibit the recruitment of macrophages ${ }^{(48,49)}$ or decrease the pro-inflammatory activity ${ }^{(50,51)}$ of macrophages improve 
the insulin sensibility in obesity. In our study, the expression of genes relative to lipid metabolism and TNF $\alpha$ in adipocytes and in adipose macrophages was measured. The level of TNF $\alpha$ gene expression did not differ among groups when measured in adipocytes. However, we observed an increase in the level of gene expression of TNF $\alpha$ and PPAR $\gamma$ in macrophages of both HF and HFn-3 groups, with no effect of $n-3$ PUFA against inflammatory and pro-adipogenic activity of macrophages. In other studies, $n-3$ PUFA were described to have a protective effect against adipose tissue inflammation induced by a HFD in obese diabetic mice ${ }^{(52)}$ and against TNF $\alpha$ production ${ }^{(53)}$.

In this study, the HFD led to a trend to increase $\mathrm{HDL}_{\mathrm{CH}}$ when compared to the control diet. This result is in accordance with what we and others have reported in hamsters fed with a HFD or cholesterol-enriched diet, with increases in TAG, total cholesterol and $\mathrm{HDL}_{\mathrm{CH}}{ }^{(54-56)}$. We showed that EPA and DHA decrease fasting and postprandial plasma TAG and $\mathrm{HDL}_{\mathrm{CH}}$. The decrease of total cholesterol has been reported in other studies in hamsters ${ }^{(57,58)}$ and mice ${ }^{(59)}$ to be associated with a decrease in $\mathrm{HDL}_{\mathrm{CH}}$. It was reported that this decrease was associated with an overexpression of SR-B1 ${ }^{(59,60)}$, whereas a study in obese rats reported an increase in SR-B1 activity, but with no change in $\mathrm{HDL}_{\mathrm{CH}}$ level $^{(61)}$. Most studies of reverse cholesterol transport (RCT) are conducted in mice or rats. These species do not express cholesteryl ester transfer protein, a protein that transfers cholesteryl ester from HDL to VLDL/LDL, followed by a hepatic uptake of these lipoproteins. As this pathway is the major route of RCT in human subjects, a cholesteryl ester transfer protein-expressing species, such as the hamster, represents a convenient preclinical model for investigating novel therapies for the treatment of dyslipidaemia in human subjects. It has been revealed that the overexpression of hepatic SR-BI increases RCT and has an anti-atherosclerotic role, despite low $\mathrm{HDL}_{\mathrm{CH}}$ concentrations ${ }^{(62-64)}$. We recently reported in hamsters fed with a cholesterol-enriched diet a high $\mathrm{HDL}_{\mathrm{CH}}$ and low SR-B1 gene expression associated with a decrease in $\mathrm{RCT}$ efficiency ${ }^{(56)}$. In the present study, we found an increase of SR-B1 expression in liver. These data suggested that $n-3$ PUFA stimulates one step in the rate of cholesterol ester transport from peripheral tissues to the liver, probably by increasing the amount of SR-B1. The level of LDL and VLDL cholesterol did not change with $n$-3 PUFA enrichment, whereas some studies described an increase in LDL-cholesterol in fish oil-fed hamsters ${ }^{(65)}$ and in type 2 diabetic patients ${ }^{(66)}$

The hypotriacylglycerolaemic effect of $n$-3 PUFA shown in several studies in both rodents ${ }^{(4,5)}$ and human subjects ${ }^{(6,7)}$ was confirmed in this study. We also showed a lower liver TAG content with $n$-3 PUFA related to a decrease in VLDL secretion. This decrease may be explained by both a decrease in lipid synthesis and catabolism. We measured the gene expression of SREBP-1c, the main transcriptional factor controlling lipid synthesis in the liver. We observed an increase in SREBP-1c expression in the presence of the HFD and a decrease in the presence of $n-3$ PUFA. We noted that $n-3$ PUFA reduced diacylglycerol $O$-acyltransferase 2 , an enzyme that catalyses the final step of TAG synthesis. Furthermore, CPT-1, an enzyme involved in the transport of fatty acids into the mitochondria, was higher in the HFn-3 compared to the HF group and did not differ from the Control group. This result suggested an active mitochondrial $\beta$-oxidation. The same results were observed in mice fed with a DHAsupplemented diet ${ }^{(67)}$. This was not observed in rats fed with EPA, in which no effect was observed in SREBP-1c expression $^{(68)}$. Unexpectedly, the effect of $n-3$ PUFA on lipogenesis and hepatic lipid accumulation was not related to the activation of PPAR $\gamma$, but seems to result from the inhibition of SREBP-1c expression. The same result was obtained recently in mice fed with EPA and was explained by the inhibition of maturation of SREBP-1c by $n$ - 3 fatty acids ${ }^{(69)}$.

The decrease of VLDL secretion by the liver was also reported in other studies. In vitro, HepG2 cells treated with DHA resulted in overall reduced apoB100 secretion ${ }^{(70)}$. In rats, DHA decreased VLDL secretion ${ }^{(71,72)}$. Diabetic patients treated with EPA and DHA showed a decrease in VLDL apoB100 concentration related to a decrease in VLDL production $^{(73)}$. Recently, another mechanism implying lipid peroxidation and oxidative stress on ApoB100 degradation via a post-endoplasmic reticulum presecretory proteolysis, was described to be relevant to the hypotriacylglycerolaemic effect of dietary $n-3$ fatty acids ${ }^{(74,75)}$. Consistent with these data, we showed an increase in the level of MDA in the HF $n$ - 3 group compared to the Control and HF groups.

In this study, although the postprandial lipaemia magnitude, as calculated by the AUC, was similar between the HF and HF $n$ - 3 groups, the triacylglycerolaemia at 6,8 and $10 \mathrm{~h}$ of kinetic were lower in the HFn-3 group. Postprandial TAG concentration reflects production and clearance of chylomicrons. Harris et al. ${ }^{(9)}$ suggested that $n-3$ PUFA accelerate chylomicron lipid clearance by facilitating LPL-mediated lipolysis. Similarly, a study in mice also showed an enhancement of blood clearance of TAG-rich particles ${ }^{(76)}$. As no difference was observed in LPL gene expression in our study, we suggested that $n$-3 PUFA lowered postprandial lipaemia by decreasing the release of TAG-rich lipoproteins.

In our experimental conditions, the evaluation of endothelial function did not show a difference between the Control and $\mathrm{HF}$ groups despite the difference in glucose tolerance and lipid plasma concentrations. However, in the presence of $n-3$ PUFA, we observed better endothelium-dependent vascular response in accordance with previously reported data ${ }^{(77)}$. The endothelium relaxation was negatively correlated with the impairment of glucose tolerance and plasma cholesterol concentration. This improvement can be explained by the incorporation of $n-3$ PUFA into cell membranes, thus affecting function of cell and tissues with subsequent impact on the production of various vasoactive eicosanoids and other mediators $^{(78)}$.

In conclusion, we demonstrated that, although no effect was observed on inflammation (TNF $\alpha$ in macrophages), $n-3$ PUFA have a preventive effect on the development of BW gain, glucose intolerance and dyslipidaemia induced by a HFD with decrease of hepatic secretion of VLDL TAG by reducing the expression of genes involved in lipogenesis, 
especially SREBP-1c and diacylglycerol $O$-acyltransferase 2 . These disturbances induced by the HFD were not associated with endothelial function impairment in the HF group, but we showed a beneficial effect on this function with $n$-3 PUFA enrichment. Finally, we showed, under $n$-3 PUFA supplementation, a decrease in $\mathrm{HDL}_{\mathrm{CH}}$ concentration related to an increase in SR-B1 gene expression, suggesting an improvement of RCT. This later effect needs more investigation to elucidate the effect of $n$ - 3 PUFA on HDL turnover and RCT.

\section{Acknowledgements}

The authors thank Nathalie Vaillant for her technical assistance. The present study was supported by CRNH (Centre de Recherche en Nutrition Humaine, Nantes, France) and research programme NUPEM supported by Region Pays de la Loire. The $n-3$ PUFA were provided by Pierre Fabre Santé. F. K. C. conducted the experiment, data analysis and wrote the manuscript; A. A. provided technical assistance in the animal experient; X. P. carried out the measurement of gene expression; A. M. carried out the diet analysis; G. L. advised on the evaluation of endothelial function; M. K. provided significant advice and consultation; P. N. helped to draft the manuscript and provided significant advice; K. O. conceived the study, and participated in the design, coordination and the writing of the manuscript. All authors have contributed to the preparation of the manuscript and agreed with the content of the submitted manuscript. The authors declare no conflict of interest.

\section{References}

1. Eckel RH, Grundy SM \& Zimmet PZ (2005) The metabolic syndrome. Lancet 365, 1415-1428.

2. Luscher TF \& Barton M (1997) Biology of the endothelium. Clin Cardiol 20, II-3-10.

3. Billman GE, Kang JX \& Leaf A (1997) Prevention of ischemiainduced cardiac sudden death by $n-3$ polyunsaturated fatty acids in dogs. Lipids 32, 1161-1168.

4. Rustan AC, Christiansen EN \& Drevon CA (1992) Serum lipids, hepatic glycerolipid metabolism and peroxisomal fatty acid oxidation in rats fed omega- 3 and omega- 6 fatty acids. Biochem J 283, Pt. 2, 333-339.

5. Flachs P, Mohamed-Ali V, Horakova O, et al. (2006) Polyunsaturated fatty acids of marine origin induce adiponectin in mice fed a high-fat diet. Diabetologia 49, 394-397.

6. Woodman RJ, Mori TA, Burke V, et al. (2002) Effects of purified eicosapentaenoic and docosahexaenoic acids on glycemic control, blood pressure, and serum lipids in type 2 diabetic patients with treated hypertension. Am J Clin Nutr 76, 1007-1015.

7. Balk EM, Lichtenstein AH, Chung M, et al. (2006) Effects of omega-3 fatty acids on serum markers of cardiovascular disease risk: a systematic review. Atherosclerosis 189, 19-30.

8. Hanwell HE, Kay CD, Lampe JW, et al. (2009) Acute fish oil and soy isoflavone supplementation increase postprandial serum $(n-3)$ polyunsaturated fatty acids and isoflavones but do not affect triacylglycerols or biomarkers of oxidative stress in overweight and obese hypertriglyceridemic men. J Nutr 139, 1128-1134.
9. Harris WS, Lu G, Rambjor GS, et al. (1997) Influence of $n$-3 fatty acid supplementation on the endogenous activities of plasma lipases. Am J Clin Nutr 66, 254-260.

10. Balkau B, Charles MA, Drivsholm T, et al. (2002) Frequency of the WHO metabolic syndrome in European cohorts, and an alternative definition of an insulin resistance syndrome. Diabetes Metab 28, 364-376.

11. Fedor D \& Kelley DS (2009) Prevention of insulin resistance by $n-3$ polyunsaturated fatty acids. Curr Opin Clin Nutr Metab Care 12, 138-146.

12. Abate N, Chandalia M, Snell PG, et al. (2004) Adipose tissue metabolites and insulin resistance in nondiabetic Asian Indian men. J Clin Endocrinol Metab 89, 2750-2755.

13. Siscovick DS, Raghunathan TE, King I, et al. (1995) Dietary intake and cell membrane levels of long-chain $n$-3 polyunsaturated fatty acids and the risk of primary cardiac arrest. JAMA 274, 1363-1367.

14. von Schacky C, Angerer P, Kothny W, et al. (1999) The effect of dietary omega-3 fatty acids on coronary atherosclerosis. A randomized, double-blind, placebo-controlled trial. Ann Intern Med 130, 554-562.

15. Ruidavets JB, Bongard V, Dallongeville J, et al. (2007) High consumptions of grain, fish, dairy products and combinations of these are associated with a low prevalence of metabolic syndrome. J Epidemiol Community Health 61, $810-817$

16. Mori TA, Watts GF, Burke V, et al. (2000) Differential effects of eicosapentaenoic acid and docosahexaenoic acid on vascular reactivity of the forearm microcirculation in hyperlipidemic, overweight men. Circulation 102, 1264-1269.

17. Christon R, Marette A, Badeau M, et al. (2005) Fatty acidinduced changes in vascular reactivity in healthy adult rats. Metabolism 54, 1600-1609.

18. Abeywardena MY \& Head RJ (2001) Dietary polyunsaturated fatty acid and antioxidant modulation of vascular dysfunction in the spontaneously hypertensive rat. Prostaglandins Leukot Essent Fatty Acids 65, 91-97.

19. Goirand F, Ovide-Bordeaux S, Renaud JF, et al. (2005) Effect of dietary docosahexaenoic acid on the endotheliumdependent vasorelaxation in diabetic rats. Clin Exp Pharmacol Physiol 32, 184-190.

20. Kusunoki M, Tsutsumi K, Hara T, et al. (2003) Ethyl icosapentate (omega-3 fatty acid) causes accumulation of lipids in skeletal muscle but suppresses insulin resistance in OLETF rats. Otsuka Long-Evans Tokushima Fatty. Metabolism 52, 30-34.

21. Briand F (2010) The use of dyslipidemic hamsters to evaluate drug-induced alterations in reverse cholesterol transport. Curr Opin Investig Drugs 11, 289-297.

22. Nistor A, Bulla A, Filip DA, et al. (1987) The hyperlipidemic hamster as a model of experimental atherosclerosis. Atherosclerosis 68, 159-173.

23. Ferrier L, Robert P, Dumon H, et al. (2002) Evaluation of body composition in dogs by isotopic dilution using a lowcost technique, Fourier-transform infrared spectroscopy. J Nutr 132, 1725S-1727S.

24. Briand F, Magot T, Krempf M, et al. (2006) Effects of atorvastatin on high-density lipoprotein apolipoprotein A-I metabolism in dogs. Eur J Clin Invest 36, 224-230.

25. Schotz MC, Scanu A \& Page IH (1957) Effect of triton on lipoprotein lipase of rat plasma. Am J Physiol 188, 399-402.

26. Millar JS, Maugeais C, Fuki IV, et al. (2002) Normal production rate of apolipoprotein $\mathrm{B}$ in LDL receptor-deficient mice. Arterioscler Thromb Vasc Biol 22, 989-994.

27. Siri P, Candela N, Zhang YL, et al. (2001) Post-transcriptional stimulation of the assembly and secretion of triglyceride-rich 
apolipoprotein B lipoproteins in a mouse with selective deficiency of brown adipose tissue, obesity, and insulin resistance. J Biol Chem 276, 46064-46072.

28. Folch J, Lees M \& Sloane Stanley GH (1957) A simple method for the isolation and purification of total lipides from animal tissues. J Biol Chem 226, 497-509.

29. Mori TA, Bao DQ, Burke V, et al. (1999) Dietary fish as a major component of a weight-loss diet: effect on serum lipids, glucose, and insulin metabolism in overweight hypertensive subjects. Am J Clin Nutr 70, 817-825.

30. McCombie G, Browning LM, Titman CM, et al. (2009) Omega-3 oil intake during weight loss in obese women results in remodelling of plasma triglyceride and fatty acids. Metabolomics 5, 363-374.

31. Storlien LH, Kraegen EW, Chisholm DJ, et al. (1987) Fish oil prevents insulin resistance induced by high-fat feeding in rats. Science 237, 885-888.

32. Hassanali Z, Ametaj BN, Field CJ, et al. (2010) Dietary supplementation of $n-3$ PUFA reduces weight gain and improves postprandial lipaemia and the associated inflammatory response in the obese JCR:LA-cp rat. Diabetes Obes Metab 12, 139-147.

33. Okuno M, Kajiwara K, Imai S, et al. (1997) Perilla oil prevents the excessive growth of visceral adipose tissue in rats by down-regulating adipocyte differentiation. J Nutr 127, $1752-1757$.

34. Rossmeisl M, Jelenik T, Jilkova Z, et al. (2009) Prevention and reversal of obesity and glucose intolerance in mice by DHA derivatives. Obesity (Silver Spring) 17, 1023-1031.

35. Todorcevic M, Kjaer MA, Djakovic N, et al. (2009) n-3 HUFAs affect fat deposition, susceptibility to oxidative stress, and apoptosis in Atlantic salmon visceral adipose tissue. Comp Biochem Physiol B Biochem Mol Biol 152, 135-143.

36. Burghardt PR, Kemmerer ES, Buck BJ, et al. (2010) Dietary n-3:n-6 fatty acid ratios differentially influence hormonal signature in a rodent model of metabolic syndrome relative to healthy controls. Nutr Metab (Lond) 7, 53.

37. Sato A, Kawano H, Notsu T, et al. (2010) Antiobesity effect of eicosapentaenoic acid in high-fat/high-sucrose diet-induced obesity: importance of hepatic lipogenesis. Diabetes 59 , 2495-2504.

38. Ntambi JM, Miyazaki M, Stoehr JP, et al. (2002) Loss of stearoyl-CoA desaturase-1 function protects mice against adiposity. Proc Natl Acad Sci US A 99, 11482-11486.

39. Kajikawa S, Harada T, Kawashima A, et al. (2009) Highly purified eicosapentaenoic acid prevents the progression of hepatic steatosis by repressing monounsaturated fatty acid synthesis in high-fat/high-sucrose diet-fed mice. Prostaglandins Leukot Essent Fatty Acids 80, 229-238.

40. Samane S, Christon R, Dombrowski L, et al. (2009) Fish oil and argan oil intake differently modulate insulin resistance and glucose intolerance in a rat model of dietary-induced obesity. Metabolism 58, 909-919.

41. Kalupahana NS, Claycombe K, Newman SJ, et al. (2010) Eicosapentaenoic acid prevents and reverses insulin resistance in high-fat diet-induced obese mice via modulation of adipose tissue inflammation. J Nutr 140, 1915-1922.

42. Manco M, Calvani M \& Mingrone G (2004) Effects of dietary fatty acids on insulin sensitivity and secretion. Diabetes Obes Metab 6, 402-413.

43. Lombardo YB \& Chicco AG (2006) Effects of dietary polyunsaturated $n-3$ fatty acids on dyslipidemia and insulin resistance in rodents and humans. A review. J Nutr Biochem 17, $1-13$.
44. Goodpaster BH, Theriault R, Watkins SC, et al. (2000) Intramuscular lipid content is increased in obesity and decreased by weight loss. Metabolism 49, 467-472.

45. Goodpaster BH, Kelley DE, Wing RR, et al. (1999) Effects of weight loss on regional fat distribution and insulin sensitivity in obesity. Diabetes $\mathbf{4 8}, 839-847$.

46. Weisberg SP, McCann D, Desai M, et al. (2003) Obesity is associated with macrophage accumulation in adipose tissue. J Clin Invest 112, 1796-1808.

47. Cancello R, Tordjman J, Poitou C, et al. (2006) Increased infiltration of macrophages in omental adipose tissue is associated with marked hepatic lesions in morbid human obesity. Diabetes 55, 1554-1561.

48. Kanda H, Tateya S, Tamori Y, et al. (2006) MCP-1 contributes to macrophage infiltration into adipose tissue, insulin resistance, and hepatic steatosis in obesity. J Clin Invest 116, 1494-1505.

49. Weisberg SP, Hunter D, Huber R, et al. (2006) CCR2 modulates inflammatory and metabolic effects of high-fat feeding. $J$ Clin Invest 116, 115-124.

50. Arkan MC, Hevener AL, Greten FR, et al. (2005) IKK-beta links inflammation to obesity-induced insulin resistance. Nat Med 11, 191-198.

51. Odegaard JI, Ricardo-Gonzalez RR, Red Eagle A, et al. (2008) Alternative M2 activation of Kupffer cells by PPARdelta ameliorates obesity-induced insulin resistance. Cell Metab 7 , 496-507.

52. Todoric J, Loffler M, Huber J, et al. (2006) Adipose tissue inflammation induced by high-fat diet in obese diabetic mice is prevented by $n-3$ polyunsaturated fatty acids. Diabetologia 49, 2109-2119.

53. Hao W, Wong OY, Liu X, et al. (2010) Omega-3 fatty acids suppress inflammatory cytokine production by macrophages and hepatocytes. J Pediatr Surg 45, 2412-2418.

54. Kanashiro A, Andrade DC, Kabeya LM, et al. (2009) Modulatory effects of rutin on biochemical and hematological parameters in hypercholesterolemic golden Syrian hamsters. An Acad Bras Cienc 81, 67-72.

55. Tarling EJ, Ryan KJ, Bennett AJ, et al. (2009) Effect of dietary conjugated linoleic acid isomers on lipid metabolism in hamsters fed high-carbohydrate and high-fat diets. Br J Nutr $\mathbf{1 0 1}$, 1630-1638.

56. Treguier M, Briand F, Boubacar A, et al. (2011) Diet-induced dyslipidemia impairs reverse cholesterol transport in hamsters. Eur J Clin Investig 41, 921-928.

57. Lin MH, Lu SC, Huang PC, et al. (2005) A high-cholesterol, $n-3$ polyunsaturated fatty acid diet causes different responses in rats and hamsters. Ann Nutr Metab 49, 386-391.

58. Mast N, Shafaati M, Zaman W, et al. (2010) Marked variability in hepatic expression of cytochromes CYP7A1 and CYP27A1 as compared to cerebral CYP46A1. Lessons from a dietary study with omega 3 fatty acids in hamsters. Biochim Biophys Acta 1801, 674-681.

59. le Morvan V, Dumon MF, Palos-Pinto A, et al. (2002) n-3 FA increase liver uptake of HDL-cholesterol in mice. Lipids $\mathbf{3 7}$, $767-772$.

60. Spady DK, Kearney DM \& Hobbs HH (1999) Polyunsaturated fatty acids up-regulate hepatic scavenger receptor B1 (SR-BI) expression and HDL cholesteryl ester uptake in the hamster. J Lipid Res 40, 1384-1394.

61. Sheril A, Jeyakumar SM, Jayashree T, et al. (2009) Impact of feeding polyunsaturated fatty acids on cholesterol metabolism of dyslipidemic obese rats of WNIN/GR-Ob strain. Atherosclerosis 204, 136-140.

62. Arai T, Wang N, Bezouevski M, et al. (1999) Decreased atherosclerosis in heterozygous low density lipoprotein 
receptor-deficient mice expressing the scavenger receptor BI transgene. J Biol Chem 274, 2366-2371.

63. Wang N, Arai T, Ji Y, et al. (1998) Liver-specific overexpression of scavenger receptor BI decreases levels of very low density lipoprotein ApoB, low density lipoprotein ApoB, and high density lipoprotein in transgenic mice. $J$ Biol Chem 273, 32920-32926.

64. Nishimoto T, Pellizzon MA, Aihara M, et al. (2009) Fish oil promotes macrophage reverse cholesterol transport in mice. Arterioscler Thromb Vasc Biol 29, 1502-1508.

65. de Silva PP, Agarwal-Mawal A, Davis PJ, et al. (2005) The levels of plasma low density lipoprotein are independent of cholesterol ester transfer protein in fish-oil fed F1B hamsters. Nutr Metab (Lond) 2, 8.

66. Kissebah AH, Alfarsi S, Evans DJ, et al. (1983) Plasma low density lipoprotein transport kinetics in noninsulin-dependent diabetes mellitus. J Clin Invest 71, 655-667.

67. Sun C, Wei ZW \& Li Y (2011) DHA regulates lipogenesis and lipolysis genes in mice adipose and liver. Mol Biol Rep 38, 731-737.

68. Perez-Echarri N, Perez-Matute P, Marcos-Gomez B, et al. (2009) Down-regulation in muscle and liver lipogenic genes: EPA ethyl ester treatment in lean and overweight (high-fat-fed) rats. J Nutr Biochem 20, 705-714.

69. Tanaka N, Zhang X, Sugiyama E, et al. (2010) Eicosapentaenoic acid improves hepatic steatosis independent of PPARalpha activation through inhibition of SREBP-1 maturation in mice. Biochem Pharmacol 80, 1601-1612.

70. Wu X, Shang A, Jiang H, et al. (1997) Demonstration of biphasic effects of docosahexaenoic acid on apolipoprotein B secretion in HepG2 cells. Arterioscler Thromb Vasc Biol 17, 3347-3355.
71. Ikeda I, Kumamaru J, Nakatani N, et al. (2001) Reduced hepatic triglyceride secretion in rats fed docosahexaenoic acid-rich fish oil suppresses postprandial hypertriglyceridemia. J Nutr 131, 1159-1164.

72. Zheng X, Avella M \& Botham KM (2001) Comparison of the effects of dietary $n-3$ and $n-6$ polyunsaturated fatty acids on very-low-density lipoprotein secretion when delivered to hepatocytes in chylomicron remnants. Biochem $J \mathbf{3 5 7}$, 481-487.

73. Ouguerram K, Maugeais C, Gardette J, et al. (2006) Effect of $n-3$ fatty acids on metabolism of apoB100-containing lipoprotein in type 2 diabetic subjects. Br J Nutr 96, 100-106.

74. Pan M, Cederbaum AI, Zhang YL, et al. (2004) Lipid peroxidation and oxidant stress regulate hepatic apolipoprotein $\mathrm{B}$ degradation and VLDL production. J Clin Invest 113, $1277-1287$.

75. Krauss RM (2004) Hold the antioxidants and improve plasma lipids? J Clin Invest 113, 1253-1255.

76. Qi K, Fan C, Jiang J, et al. (2008) Omega-3 fatty acid containing diets decrease plasma triglyceride concentrations in mice by reducing endogenous triglyceride synthesis and enhancing the blood clearance of triglyceride-rich particles. Clin Nutr 27, 424-430.

77. Conde CM, Cyrino FZ, Bottino DA, et al. (2007) Longchain $n-3$ polyunsaturated fatty acids and microvascular reactivity: observation in the hamster cheek pouch. Microvasc Res $\mathbf{7 3}$, 237-247.

78. Din JN, Newby DE \& Flapan AD (2004) Omega 3 fatty acids and cardiovascular disease - fishing for a natural treatment. BMJ 328, 30-35. 